\title{
La música neogranadina: un espacio poblado por mujeres
}

\author{
Sergio Pérez Álvarez / Universidad Tecnológica de Pereira
}

Clara E. Herrera / University of Illinois-Chicago

\section{(...) porque no es voz que viene en torbellino, sino en aire de silbo blando; no se gusta en el sonido de los labios, tanto como en los movimientos del corazón. - Madre Francisca Josefa del Castillo, Afectos Espirituales}

\section{Prácticas musicales femeninas en contextos hispanoamericanos}

Los estudios sobre la presencia de la mujer en el mundo musical colonial hispanoamericano se han incorporado en la musicología de forma considerablemente tardía. Josefina Muriel dedicó un capítulo de su seminal obra Cultura femenina novohispana (2000) a una visión general de las labores no literarias realizadas por la mujer, entre ellas la de la práctica musical. La autora encontró que la música tuvo lugar primordial en las instituciones femeninas de la Nueva España: "los colegios, los conventos, los beaterios y aun los recogimientos, dedicaban a ella buena parte de su tiempo, pues formaba parte de las numerosísimas ceremonias que implicaba la vida religiosa en aquella época" $(2000,482)$. Para Muriel, el conocimiento de la rama musical de la cultura femenina "amerita una obra completa que debe ser realizada por especialistas en la música" (2000, 483). Años más tarde, ella misma, con el historiador de arte Luis Lledías, producen una obra que en parte subsana este deseo: La música en las instituciones femeninas novohispanas (2009). En esta obra, los autores rastrean la significativa presencia de las mujeres en la cultura y el desarrollo del mundo musical de la Nueva España. También recopilan una valiosa colección de repertorios provenientes de diferentes instituciones, y de los trabajos de educación y praxis musical de las niñas y mujeres.

El trabajo de Alejandro Vera sobre el convento de La Merced de Santiago de Chile (2004) resalta la escasa información sobre la música colonial en Chile y la ausencia de investigaciones exhaustivas. El autor asegura que faltan trabajos detallados sobre temas fundamentales como la actividad musical en los monasterios y en las festividades públicas y privadas, e investigaciones sobre instrumentos disponibles en el periodo $(2004,35)$. Vera documenta que en 1676 el convento de La Merced ya contaba con un órgano pequeño, dos cornetas nuevas, un fogote, una dulzaina, un arpa, un bajón, una vihuela, una buena guitarra, más otra vihuela vieja. Había, además, un cuaderno de canto de órgano, cinco legajos con música de fiestas religiosas y cuatro libros de canto llano. Esto contradice la creencia de que en los monasterios se desarrollaba la actividad musical con una infraestructura muy precaria, sin cantores de nivel y con escaso instrumental $(2004,17)$.

En 2005, Viana Cadenas intenta subsanar la carencia de estudios en las instituciones femeninas venezolanas y publica un estudio sobre la música en el Convento de la Inmaculada Concepción de Caracas (siglos XVII-XIX). El rol de la música en este convento, a pesar de tratarse de un centro urbano menor, "constituye un aspecto bastante significativo para el estudio musicológico en general" (2005, 5). Viana Cadenas demuestra que la actividad musical en los conventos de Caracas y en otras instituciones religiosas coloniales eran un reflejo de las instituciones europeas en las particulares condiciones socioeconómicas y culturales del contexto urbano caraqueño. Es bien conocido que en los conventos, por lo general, se reproducía la jerarquía de la sociedad colonial. Las funciones y responsabilidades de las manifestaciones culturales eran discriminadas según ese orden. Es interesante notar que en el convento en Caracas, aparte de las actividades musicales tradicionales, se realizaban conciertos abiertos al público en las porterías, con participación eventual de músicos extra-clausura, con cantos y ejecución de instrumentos por las criadas $(2005,12)$. La actividad musical principal del convento estaba íntimamente relacionada con la actividad de la capilla musical de la Catedral. En 1671 se establece el cargo de Maestro de Capilla y, ya en 1688, la capilla musical registra la primera mención a una Maestra de Capilla (2005, 28).

La catedrática argentina Marisa Restiffo, en su artículo "De la música al poder: los oficios musicales como estrategia de ascenso político en el monasterio de Santa Catalina de Sena (Córdoba, siglo XVIII)," postula que "los oficios de cantora y subcantora en el monasterio constituían un escalón al que podía acceder una monja para comenzar su ascenso en la escala del poder en el gobierno del monasterio" (2018, 144). Cantora y subcantora guiaban respectivamente cada uno de los coros y tocaban el órgano en los momentos permitidos. Los fieles, que estaban del otro lado de la reja, las identificaban por sus voces durante la misa, lo que se constituía en "una manera de ejercer su liderazgo y de vencer la invisibilidad" (2018, 161). La autora demuestra que las funciones 
musicales se vinculaban de manera importante con las relaciones de poder en el interior del convento.

El estudio de las prácticas musicales femeninas en el espacio colonial hispanoamericano ha demostrado entonces que el contacto con la música era una parte significativa de la vida conventual, y ha confirmado que las mujeres son partícipes del desarrollo tanto del arte como de la cultura, que se teje a partir de la apropiación de la música hispánica en las colonias. Como parte de este circuito que desplegó la colonización española, el contexto neogranadino fue parte de este fenómeno. Constanza Toquica y Fernando Restrepo (2001), en la iglesia del Convento de Santa Clara en Bogotá, y Alejandra Isaza, a partir de una investigación del estudio en Villa de Nuestra Señora de la Candelaria de Medellín recogida en su libro Suite para los sonidos: música en Medellín, siglos XVII y XVIII (2010), analizan prácticas culturales alrededor de la composición, la producción y el consumo de música, en las que participaron mujeres. También dan pistas sobre un aspecto que ha sido menos explorado en la historiografía colonial y es el relacionado con la influencia de las prácticas musicales femeninas en contextos seculares donde la mujer también tuvo influencia.

Con el ánimo de explorar la presencia de la música en el espacio neogranadino, este trabajo indaga, a partir de un análisis de fuentes primarias y secundarias - muchas de ellas conocidas pero que son presentadas con un prisma distintoen algunas prácticas musicales que nos permiten ver de qué manera las mujeres también hicieron parte del desarrollo de una cultura musical en este contexto colonial. Aunque la información disponible es escasa (de allí que nuestro enfoque sea en la mujer de élite, cuya aparición es marginal en los archivos que registran a los hombres), las prácticas musicales en las que participaron mujeres fueron parte de la vida social de los conventos y de múltiples actividades religiosas que regulaban el espacio social y cultural en la Colonia. A medida que va avanzando la colonización, las mujeres incursionan en la música secular, participando de una "afición" a la música, que fue definitiva para el desarrollo, la circulación y la apropiación cultural de este arte. Al extender el rango de estudio sobre las prácticas musicales, se abren nuevos interrogantes sobre la vida social de las mujeres en el contexto colonial, que contrastan la imagen de la mujer sumida en las actividades del hogar y al arbitrio del marido. Para la musicología, el reconocimiento de las mujeres también invita a hacer nuevas preguntas.

Este recorrido comienza con la música desde los conventos instalados a partir del siglo XVI, y en donde las mujeres de élite que querían dedicarse a este arte encontraron refugio, por ser el convento una de las instituciones en la que más se insistió en promover las actividades musicales en la Colonia; se detiene en el asunto de la formación musical de las mujeres que, aunque fue un privilegio exclusivo de los conventos, no fue obstáculo para que las mujeres fuera de los claustros ampliaran su conocimiento y valoración de las artes musicales; y finaliza con las primeras apariciones en la escena pública de mujeres como músicas o cantantes, las cuales demuestran que el reconocimiento social de la mujer en las artes también tiene importantes antecedentes.

\section{Voces desde los conventos e iglesias}

Para apoyar la misión evangelizadora de la Iglesia, en pocos años se fundaron decenas de comunidades religiosasentre los siglos XVI y XVIII se establecieron quince conventos de monjas en la Nueva Granada. ${ }^{1}$ Desde la Edad Media, en Europa, los conventos ofrecían a las mujeres un modo de vida diferente, en el que la oportunidad de cantar, tocar instrumentos y componer música para la adoración de Dios era un elemento crucial. De acuerdo con Nieves Baranda, "[a] pesar de que imaginamos los conventos como lugares de recogimiento y silencio por la exigencia de la regla, el repaso a las coplas y versos compuestos por las monjas muestra que en ellos había lugar al bullicio" $(2013,27)$. Para algunos conventos la producción de música litúrgica fue la actividad central de la comunidad (Yardley 1986, 15). ${ }^{2}$ El convento ha sido considerado uno de los focos de la cultura barroca y uno de los principales centros de la producción musical femenina (Ramos López 2003, 72).

El vínculo entre la práctica musical religiosa y la secular permitió a los conventos coloniales hispanoamericanos replicar una dinámica habitual en los conventos europeos. La música fue considerada un elemento esencial de la vida religiosa y de la liturgia. Se sabe que la actividad musical fue valorada como un trabajo "profesional," valoración semejante a la de otros trabajos relacionados con la gobernabilidad del claustro. Por ejemplo, una monja del período colonial para quien la música ocupó un lugar muy importante fue la Jerónima novohispana Sor Juana Inés de la Cruz. Los críticos coinciden en reconocer el amplio conocimiento musical que la escritora poseía. Sin embargo, en el campo práctico no se ha llegado a un consenso y los resultados siguen siendo hipotéticos. ${ }^{3}$ Sor Juana compuso villancicos, canciones que adquirieron una dimensión popular y que se cantaban en diversas fiestas religiosas - en la liturgia no solemne-, con el objetivo de entretener a los fieles. Algunos de estos fueron musicalizados en diferentes regiones del Nuevo Mundo, entre ellos la Nueva Granada (Bénassy-Berling 1996, 29), lo que hace pensar que pudieron ser "terreno seguro" para ser interpretados por mujeres fuera del claustro.

El estudio de la canción religiosa, en particular del villancico, ayuda a comprender la vida conventual y la emergente cultura urbana en la América Española (Toquica y Restrepo 2001, 96). Constanza Toquica (2001) transcribió algunas de las canciones interpretadas por el coro alto de la Iglesia del Convento de Santa Clara de Santafé, que incluyen, entre otras, canciones de Sor Juana —algunas apócrifas-, obras 
del maestro Francisco Saiz, obras musicalizadas y adaptadas por el maestro de música Juan de Herrera, y la partitura de una canción de la madre Inés de la Trinidad con letra del maestro Pinillos de Cádiz. Para Toquica y Restrepo, estas canciones son evidencia de que las clarisas santafereñas participan de un 'mercado cultural' alrededor de la producción de la música religiosa "que trasciende los muros del convento y del mundo santafereño" (2001, 99). Las canciones religiosas, en especial villancicos, circularon por todo el continente y fertilizaron la cultura musical religiosa, cuya práctica también fue activa en el contexto neogranadino.

Si bien en la doctrina cristiana se buscaba el control de los cuerpos y las sensibilidades, el canto y la música despertaban sensaciones que eran ampliamente compartidas por las mujeres del convento, y que jugaban un papel en la construcción de sus relaciones intra y extramuros. En la rigidez disciplinar del claustro, cantar permitía a las mujeres religiosas explorar emociones que, incluso siendo restringidas, eran determinantes para la construcción de algunas subjetividades femeninas. Este "gusto musical," o interés por la música, no solo era un asunto de cantantes y compositoras, muchas de las cuales alcanzaron conocimientos musicales destacados. Cantantes del coro, intérpretes de los instrumentos, aspirantes a participar en el coro, o simplemente "consumidoras" y aficionadas a las canciones religiosas -entre las que se encuentra un amplio espectro de identidades femeninas- pudieron despertar un gusto musical, y encontrar refugio en la práctica y la recepción de este arte. Para Toquica y Restrepo "[L]as canciones del archivo del Convento de Santa Clara permiten expandir este repertorio de medios por los cuales se expresan y se definen las mujeres coloniales no sólo como productoras, sino también en cuanto consumidoras de esos bienes culturales, es decir, compositoras, intérpretes y receptoras de esa música" $(2001,102)$.

Las canciones estudiadas por Toquica y Restrepo en el convento de las clarisas permiten rastrear el contacto que tenían las religiosas con el circuito musical colonial. Aunque solo hasta ahora se estudia la manera cómo circularon y fueron apropiándose algunas canciones que en diversas versiones cruzaron el continente, sabemos que en varios conventos, incluidos los neogranadinos, estos repertorios musicales fueron 'consumidos' con fervor por las religiosas. La canción religiosa también nos deja ver los vínculos que establecía el convento con su entorno social más cercano a través de la música. La mayoría de estas canciones se interpretaban durante celebraciones litúrgicas o eventos especiales que muy a menudo tenían público asistente. Cantadas e interpretadas por mujeres, estas canciones eran parte fundamental de muchas de las procesiones, las celebraciones a la virgen y los santos, y fechas especiales como la llegada de un prelado importante o la visita del Virrey, eventos que regulaban el espacio social en la Colonia. Este público diverso que asistía a los cantos se deleitaba con los sonidos de las religiosas, y poco a poco iba familiarizándose con un repertorio musical y creando sus propias expectativas; es decir, creaba su propio gusto musical.

La mayoría de los villancicos que circularon en diversas versiones en los territorios coloniales llegaron en los repertorios musicales hispánicos y fueron adoptando características "americanas" en la medida en que se iban asimilando a las celebraciones locales e iban incorporando el sincretismo cultural de todas las colonias. ${ }^{4}$ En el estudio de los villancicos coloniales se reconoce el carácter popular que consiguen muchas de sus composiciones, gracias a que participan en ciertos acontecimientos públicos que adquieren la dimensión, en términos bajtinianos, de una 'fiesta barroca' (Grebe 1969, 25). ${ }^{5} \mathrm{Si}$ bien las obras circularon como piezas didácticas de formación cristiana, los villancicos expresan y dialogan con el entorno social en el que eran apropiados. Los indicios hasta ahora disponibles, como los que se desprenden del estudio de Alejandra Isaza (2010), evidencian que los villancicos neogranadinos hicieron parte de una múltiple actividad musical, producto de las tensiones culturales, a veces en choque, de las herencias hispánicas, indígenas y africanas, en formas poco institucionalizadas y más bien informales, pero que impactaban la vida cotidiana.

En la Nueva Granada los villancicos de extracción primeramente popular "no necesariamente estaban destinados a la época de navidad, sino para toda ocasión a través del año litúrgico. En la liturgia no solemne se enseñan gozos y estribillos" (Perdomo Escobar 1980, 51). Richard Haefer, en su reflexión sobre la música neogranadina, anota que "[e]n fiestas especiales, especialmente en las fiestas patronales locales, los feligreses asistían a estos oficios en mayor número y disfrutaban de los sonidos de música especial, polifonías sagradas y villancicos paralitúrgicos, que se insertaban especialmente después de los Responsos y de las lecciones para agregar alegría adicional a las celebraciones" $(2018,46)$. El profesor Renán Silva (2001) estudió una relación escrita de un jesuita anónimo en 1616 que narra las celebraciones de la Virgen María, en las que los sermones, indagados por Silva como instrumento de formación política, iban acompañados de coplas y canciones religiosas. De acuerdo con el relato del jesuita, estas estrategias musicales fueron mucho más efectivas que los largos sermones de los curas en latín:

[L]os franciscanos "cantaron himnos de Nuestra Señora en latín", todo el tiempo que pudieron, "que fue en la iglesia y a la salida a su plaza", la iniciativa popular se desbordó con sólo estar en el espacio público de la plaza, "porque en estando allí todo el pueblo se puso a cantar las coplas, sin poder ser reprimido de los señores oidores y alcaldes que lo procuraron", y los padres franciscanos tuvieron que suspender sus himnos "por no oirse la música, porque todos los hombres y mujeres cantaban con mucha devoción las coplas". (Silva 2001, 116-117) 
La hibridez del villancico se expresa en el rango de temáticas que pasan por problemas filosóficos de la doctrina, asuntos cotidianos de las propias religiosas, e incluso cuestiones de hondo calado erótico. En las canciones estudiadas por Toquica y Restrepo, por ejemplo, se perciben asuntos de ese imaginario cristiano y del sentimiento religioso contrarreformista, es decir, una exaltación devota, asociada la mayoría de las veces al dolor y al sufrimiento $(2001,103)$. Además de las temáticas, otro rasgo que se le atribuye al carácter híbrido del villancico es la inclusión de las palabras y registros de otras tradiciones, en particular de negritudes e indígenas. Estas son menos visibles en las encontradas en el archivo del convento de las clarisas. Sin embargo, en el Archivo musical de la Catedral Primada de Santafé de Bogotá se encuentran villancicos de los que evolucionaron en Hispanoamérica, llamados de "negros," en los que aparecen expresiones -según versiones de sus propios intérpretes- de las voces y palabras de esclavos traídos para el comercio y la minería, aunque con unas diferencias (Bermúdez 1997, 59). Eran cantos que se acompañaban con instrumentos litúrgicos tradicionales como el órgano, y con instrumentos propios de los territorios coloniales como el tiple y el arpa (Bermúdez 1995, 32).

Pero incluso en los villancicos más abstractos y más fieles al repertorio hispánico hubo incursión de voces propias del específico contexto cultural colonial. Al carecer de registro sonoro, solo nos queda imaginar los efectos que lograban las canciones de las religiosas en las gentes que las escuchaban. O tal vez seguir insistiendo en buscar el "eslabón perdido" al que se refería Perdomo: “...no sería descaminado, a medida que se transcriban los aires de los archivos coloniales, encontrar el eslabón perdido de ciertos aires andinos, en los villancicos muy sincopados, escuchados por el pueblo en los templos. Como 'bambuco se escribe con tiple,' muy seguramente el mestizo al volver de la Iglesia rasgueó esos aires populares en su guitarrillo campesino." $(1980,52)$

\section{Maestros de música y de canto}

La promoción de la música en el ambiente conventual de la Nueva Granada comenzó a fortalecerse desde el siglo XVII. El arzobispo dominico limeño Juan de Arguinao (1661-1678), que por su generosidad llegó a ser considerado segundo fundador del monasterio de Santa Inés en Santafé de Bogotá, dotó al monasterio de órgano e instrumentos musicales (Barrado 1995, 387). Igualmente "les puso a las monjas un maestro de música para que les enseñara el canto gregoriano y la salmodia," y las dotó de libros corales con el objeto de proporcionar esplendidez al culto. Sabemos que dicho maestro fue el mencionado don Juan de Herrera, a su vez capellán de las monjas (Perdomo 1980, 47). En su secuencia salmódica Laetatus sum-Nisi Dominus-Lauda (1690), este compositor colonial escribió una segunda parte para contralto, especialmente para la monja Sor María Gertrudis, de dicho convento (Stevenson 1962, 161). ${ }^{6}$ Esta es la única mujer religiosa que se conoce con nombre propio por sus cualidades como cantante: "De esta santa religiosa se dice que "en el coro cantando parecía un ángel, pues angélica era su persona y su voz" (Perdomo 1980, 47). José Ignacio Perdomo Escobar, autor de La Historia de la Música en Colombia (1980), única obra de cierta extensión sobre este tema, afirma que no se conoce la opinión de la cerrada sociedad santafereña sobre las clases de música en el mencionado claustro $(1980,46)$.

Al igual que las monjas dominicas, las clarisas recibieron clases de música del clérigo santafereño Martín Palacio Galán (Perdomo 1980, 47). En la organización jerárquica de sus conventos, después de las sacristanas, encargadas de todos los asuntos de la Iglesia, seguía el oficio de "Vicaria del Coro", encargada de vigilar la "conformidad y consonancia" en el canto del oficio divino y rezo de preces corales ("Las clarisas" 1929, 44). Jerónima Nava y Saavedra (Vble. Madre Jerónima del Espíritu Santo) fue nombrada en 1702 Vicaria de coro por haberle sobrevenido un grave accidente que le duró diez años ("Las clarisas" 1929, 80). La elección de la abadesa, suceso trascendental, incluía el canto del Te Deum laudamos, acompañado con órgano $(1929,37)$. La afición de estas monjas a la música fue evidente y se manifestó de forma constante en la administración de sus conventos. La venerable abadesa Madre Gregoria de Jesús hacía cantar cada jueves una misa solemne y cada año hacía celebrar la Inmaculada Concepción con una gran fiesta engalanada con pompas $(1929,62)$. Algunas abadesas honoraban a sus santos de devoción con magníficas fiestas. La Madre María de San Ignacio celebró, por ejemplo, la fiesta de san Antonio de Padua, durante setenta años, con vísperas cantadas (1929, $68)$.

La música jugó un papel primordial en las visiones de algunas místicas. A la venerable Hermana Teresa de Jesús Caicedo se le apareció durante una de sus visiones su "adorable dueño", Cristo Jesús, y mientras le daba espiritualmente su "sagrado viático", los ángeles celebraban con música de órgano $(1929,77)$. En la historia del convento se encuentra la narración de la muerte de la Venerable Madre Isabel de Cristo, abadesa de 1702 a 1705, donde se refiere que "un poco antes de expirar se oyó en su celda una suave música, como de varios órganos, y la celda se llenó de hermosos pajaritos que cantaban dulcemente hasta que expiró y entonces desaparecieron" $(1929,78-9)$.

Por la narración de Su Vida sabemos que la más conocida escritora mística neogranadina, la Madre clarisa tunjana Francisca Josefa de Castillo, estudiaba y tocaba el órgano en su casa y en el convento. Entre los siete y ocho años de edad se inicia en la música tomando lecciones de órgano (1968, 283). ${ }^{7}$ Luego, a la edad de 38 años, la prelada le ordena aprender a tocar de nuevo este instrumento. "Y esto me fue de mucho alivio," nos dice la religiosa, "porque pensaba poder en aquello servir y tener ese consuelo; más como ya yo tenía 
treinta y ocho años (y aunque lo había aprendido en otro tiempo, me lo habían mandado dejar, y estaba del todo olvidado), ahora con la edad, y no gustar de enseñarme la religiosa que sabía (que era muy moza), pasaba trabajo..." (cap. 30). En la mayoría de sus Afectos, como advierte Hernández-Torres (2003), aparecen imágenes relacionadas con la música (2003, 658). Con la alegoría de la "flauta dulce," central en su obra autobiográfica, traduce su experiencia mística y enfatiza la condición inexpresable y sensible de su vocación religiosa. ${ }^{8}$

A las mujeres en los conventos la formación musical les permitió ahondar en su interés en este campo cultural e incluso despertó en algunas una sincera vocación artística. Con la entrada de estos maestros, la cultura musical en el convento se robusteció, lo cual demuestra que las necesidades musicales de las religiosas se hacían más exigentes. Es de creer que un público cada vez más familiarizado con un determinado repertorio y con una comprensión cada vez más aguzada de la experiencia musical religiosa, tendría también sus propias demandas. Para garantizar la efectividad del uso de la música como estrategia de adoctrinamiento religioso, era necesario mejorar la formación y la calidad musical de las religiosas. Este incentivo de las expresiones musicales dentro de los conventos permitió a algunas religiosas reafirmar una agencia femenina particular, como el caso emblemático de la monja Castillo, pero también como la Hermana Teresa de Jesús o la Madre Isabel (Las clarisas, 1929). La música se convirtió en un mecanismo para explorar la interioridad y, al mismo tiempo, para expresar hacia el exterior su propia feminidad, en un orden masculino que las sometía y silenciaba. Con la formación musical de las monjas, se benefició a su vez un público que pudo experimentar mejores ejecuciones e interpretaciones.

La formación musical femenina fue privilegio exclusivo de la vida conventual hasta el siglo XVII. Los tratados de educación femenina en España, a diferencia de los de educación masculina, solían rechazar el aprendizaje de la música práctica para las mujeres; la teórica se consideraba fuera de sus capacidades intelectuales. ${ }^{9}$ Algunos tratadistas, como Juan Luis Vives y Juan de la Cerda, rechazaban incluso que las 'mujeres honestas' pudiesen bailar, cantar o tocar instrumentos, u oír música en su propia casa (Ramos 2003, 79). Sin embargo, es bien conocido que, tanto en España como en las colonias, era común organizar reuniones sociales entre las clases de la élite, en las cuales se compartían cantos, bailes y música. Las mujeres interpretaban diversos instrumentos, como el clavicordio, el arpa, y otros instrumentos de cuerda. Así, las mujeres han tocado para ellas mismas o para sus familias "especialmente cuando las convenciones de la época han considerado moralmente sospechoso el que una mujer interpretase música en público" $(2003,79)$. Es interesante la idea de que las religiosas podían seguir siendo músicas en su madurez, a diferencia de las mujeres casadas, quienes con frecuencia debían abandonar la profesión musical para atender a sus familias" $(2003,72)$.
En las Noticias Historiales de las conquistas de tierra firme en las Indias, el cronista Fray Pedro Simón (1574, ca.1628) describe la población de Santafé de Bogotá, y puntualiza la existencia de maestros de música, compositores y fabricantes de instrumentos desde los primeros años de la colonia (1891, 286). En cuanto a instrumentos, sabemos que el arpa cromática era común tanto en las iglesias como en las casas (Perdomo 1980, 38), muy seguramente en las casas de cierto estatus. El historiador español Juan Flores de Ocariz (1612-1692), en su conocida obra Genealogías del Nuevo Reino de Granada, refiere la existencia de diestros en la danza, en instrumentos de música y "otros ejercicios honestos" en la Nueva Granada del siglo XVII (cit. en Perdomo 1980, 45). La primera escuela pública de canto y música conocida fue iniciada por el canónigo don Francisco Felipe del Campo y Rivas (1753-1802), ya muy al final de la Colonia. Si bien no se sabe a ciencia cierta si había entrada para las mujeres (Perdomo 1980, 45), estas escuelas contribuyeron a establecer una cultura musical en la Colonia, en la que las mujeres también participaron. ${ }^{10}$

Aunque se tiene poca información sobre la instrucción musical para las mujeres en la época, existen rastros literarios que las muestran musicalmente activas en el ámbito secular: a las hijas de las familias de cierto estatus se les asignaban maestros de música o de baile y, seguramente, les era permitido actuar dentro de sus círculos sociales privados. La primera noticia sobre un maestro de música y danza en la Nueva Granada aparece en El Carnero (1859 [1980]) de Rodríguez Freyle, crónica de la conquista y los primeros años de la colonia del Nuevo Reino: "Llegó en esta sazón a aquella ciudad un Jorge Voto, maestro de danza y músico. Puso escuela y comenzó a enseñar a los mozos del lugar; y siendo ya más conocido, danzaban las mozas también" $(1980,150)$. Uno de los personajes femeninos más emblemáticos de la obra de Rodríguez Freyle, Doña Inés, logra que su esposo contrate a Jorge Voto para enseñar a danzar a su sobrina en la privacidad de su casa. Como es bien sabido, esto dio oportunidad a Voto de "revolverse con la doña Inés en torpes amores, en cuyo seguimiento trataron los dos la muerte al don Pedro de Ávila, su marido..." (1980, 150). Que el crimen que pasa impune en un primer momento sea perpetrado por el maestro de música, revela la familiaridad de su oficio en las urbes coloniales y la participación de la mujer en el ambiente musical de la época. Para atraer al maestro al lugar en donde debía ser asesinado, su victimario le solicita que lo acompañe, con estas palabras: "¿Quereisme acompañar esta noche a ver unas damas que me han rogado os lleve allá, que os quieren ver danzar y tañer?" $(1980,155)$. Así pues, aunque la mujer tenía acceso a aprender a bailar y cantar, y a disfrutar de representaciones de canto y baile, la relación con la música dependía del ámbito familiar: para las mujeres honestas, las clases se debían tomar en privado, como también en privado debía ser su asistencia a actuaciones musicales.

Es curioso que sea otro famoso crimen de la época el que ilumine también la participación de la mujer en actividades 
lúdicas relacionadas con la música. Este caso tuvo como protagonista a Luis Cortés de Mesa, oidor de la Audiencia de Santafé en 1583, cantante y guitarrista, condenado a muerte por su participación en el asesinato de Juan de los Ríos, esposo de la mujer que amaba (Puerta 1988, 66). ${ }^{11}$ En versión novelada sobre este oidor leemos cómo los bailes en las altas clases sociales hacían parte de la lúdica santafereña desde muy temprano en la época colonial. En esta narración, Clara Rosa estaba casada con un rico comerciante que le daba gusto en todo cuanto ella quería: "Diversiones, bailes, paseos, maestro de arpa" (Ortiz 1845, 180). Durante uno de los bailes que organiza en su casa, Clara Rosa baila con el oidor y lo enamora a tal punto que lo deja contemplando todo tipo de estrategias para poder estar con su nuevo amor. Al día siguiente del baile, la dama le confiesa al oidor que fue víctima de regaño de su esposo: “¿No se acuerda usted que cuando bailamos juntos a la media noche, se me cayó una cinta y que usted la alzó...? - Pues luego de que todos se fueron, se quedó a cenar y empezó a reprenderme, y tanto, que me hizo llorar" $(2003,179)$. La historia continúa y en su momento se escucha al oidor en la calle, su voz acompañada de una guitarra cantando un viejo romance de la «Muerte y el Amor» $(2003,200)$. Así, podemos ver que, aunque no libre de problemas, en la esfera privada la mujer también se divertía en contextos musicales.

Estas fuentes sin duda pueden ser utilizadas para explicar algunos aspectos de la vida social de las mujeres en la Colonia, en los que la práctica musical era un elemento importante. Nos dejan ver, por ejemplo, cómo se puede presumir que la música y la danza, en contextos seculares, aunque fue practicada en principio en la esfera privada, empezaron a ser parte de la vida cotidiana de la mujer de elite neogranadina desde el siglo XVII, en particular en los emergentes espacios culturales urbanos. El conocimiento de ciertos rituales sociales en los que intervenía la música se imponía como parte de la formación de las mujeres que pertenecían a unas élites preocupadas por emular lo más fielmente posible el estilo de vida europeo. A pesar de que no hubo formación musical formal para las mujeres fuera de los conventos, hay indicios acerca de que el gusto musical creció y se afinó con la llegada de los sonidos que venían de Europa y las demás colonias, así como con la apropiación e hibridización que tuvieron estas músicas en el encuentro con ritmos indígenas y de origen africano. En tanto reservadas al espacio íntimo, la música y la danza pasaron, de ser ignoradas, a poco a poco considerarse un asunto de mujeres, si bien las definiciones artísticas quedaban reservadas para los hombres. Como refugio, en algunos casos, la música permitió la aparición de una agencia particular, sobre todo en aquellas mujeres que se sirvieron de la música para explorar su propia intimidad, o para reafirmar una identidad en el mundo exterior gracias a la ejecución o promoción de este arte.

\section{Las cantantes "profesionales"}

Con la dinastía de los Borbón en el siglo XVIII se crearon las bases para una actividad cultural más laica, que en nuestro campo se relaciona con el florecimiento de música no religiosa para diversas celebraciones. Sin embargo, la primera mención de participación pública de mujeres en bailes en la Nueva Granada, relacionada con los bailes de máscaras, se encuentra sólo a fines del siglo XVIII. A raíz del ascenso al trono de Carlos IV y su esposa María Luisa de Parma se celebraron esmeradas fiestas en el virreinato, entre 1789 y 1790. Las fiestas incluían corridas de toros, fuegos artificiales, iluminación de calles y plazas, exhibición de retratos de los monarcas y sus escudos, cabalgatas, desfiles y representaciones teatrales. Es interesante anotar, sin embargo, que la música, el baile y los refrescos se reservaban para el "rancio grupo de autoridades, nobleza y gentes de nota" (Martínez 2003, 2). Más adelante, en 1803, se ofrecieron otros dos bailes de máscaras, en honor al virrey Amar y Borbón. ${ }^{12}$ En estos bailes participaban mujeres y hombres, con "prevenciones" articuladas por el Virrey, para su recatado funcionamiento, como retretes separados para ambos sexos, un limitado número de asistentes, y el nombramiento de tres directores de baile para cuidar del arreglo de la música y organizar a las parejas de acuerdo con sus máscaras en los lugares correspondientes (Martínez 2003, 2). ${ }^{13}$ Así, entonces, la mujer se divertía en la esfera pública.

La música era también inseparable de la representación teatral y solo en el teatro podemos encontrar algunas actuaciones de mujeres con nombre propio. Hubo que esperar hasta 1792 para que Santafé de Bogotá tuviera por fin un teatro: el Coliseo Ramirez, fundado por iniciativa del rico comerciante Tomás Ramírez y de Villar. En el reglamento se establecía que tanto mujeres como hombres podían elegir presenciar el espectáculo de pie o sentados, pagando las respectivas entradas. El Coliseo abrió sus puertas con la representación de una compañía española integrada por seis actores, seis actrices y un pequeño elenco de músicos. Es interesante notar que la primera dama cantarina, Nicolasa Villar, recibía un salario que superaba al de cualquiera de los galanes (Lamus 2012, 78). Por entonces se presentaron en Santafé las primeras tonadillas, danzas teatrales que se interpretaban en los entreactos o al final de la función y ejercían gran atracción sobre el público. Los actores y actrices que "cantaban y bailaban 'con primor' eran consagrados de manera inmediata por el público" (70), y a veces eran objeto de recriminación en los sermones de los sacerdotes, especialmente de los capuchinos (Perdomo 1980, 49). ${ }^{14}$

Entre las primeras actrices se contaban mujeres de alta alcurnia: la marquesa de San Jorge, Rafaela Isazi de Lozano, apodada la Jerezana por ser natural de Jerez de la Frontera, y la bella María de los Remedios Aguilar, esposa del ingeniero español Eleuterio Cebollino, apodada la Cebollino. En 
realidad las dos se limitaban a hacer los números sueltos de baile y canto, y no desempeñaban propiamente papeles en las comedias (Lamus 2012, 81). Según Perdomo Escobar, la Jerezana fue una de las "santafereñas más graciosas y más artistas... tocaba el piano y cantaba tonadilla y coplas con tal donaire y desparpajo, que en esos tiempos llegó a ser providencial en Santafé la frase 'tan graciosa como la jerezana'. Tuvo por par en el arte $-\mathrm{y}$ con ella cantó en el teatro en varias ocasiones- a doña María de los Remedios Aguilar, que no andaba a la zaga a fuer de andaluza picante y lengüirrota" (1980, 47). En el Coliseo, entre 1792 y 1795, se llevaron a cabo cuatro temporadas y se efectuaron 39 funciones. El número de actrices osciló entre cinco y seis (Lamus 2012, 76). La llegada de algunas de las mujeres invitadas a integrar la compañía constituía un hecho memorable. Así, a fines de 1793, la llegada de la segunda dama Patricia Ora, conocida como la Neivana, fue el más importante suceso de la segunda temporada (27 de octubre de 1793 - 4 de marzo de 1794); y la llegada del actor ciego Fermín Castellón y sus dos hijas actrices, traídos por Ramírez desde Cartagena de Indias, fue lo más novedoso en la cuarta temporada (16 de marzo a 16 de noviembre 1795) $(2012,72)$.

Aunque fuera de los conventos la asociación entre prostitución e interpretación musical femenina fue un tema recurrente, especialmente en la Europa de los siglos XVI y XVII (Ramos 2003, 72), ${ }^{15}$ en Santafé, no obstante lo manifestado por el historiador José María Cordovez Moure (1899) a fines del siglo XIX sobre que "[s]i la profesión de cómico - como se designaba entonces á los actores- se consideraba indecorosa, y la de cómica se reputaba abominable" $(1899,57)$, no existe ninguna evidencia de que estas primeras cantarinas del Coliseo se hubiesen asociado a la prostitución, quizás debido a su estatus social. Con estas pocas actuaciones famosas se cierra el Coliseo. En cuanto a la composición musical, la historia de la mujer neogranadina es una historia llena de vacíos en la bibliografía sobre la Colonia. Si existieron algunas mujeres que compusieron piezas musicales, muy posiblemente no fueron líderes en el campo, pues eran excluidas de las posiciones profesionales y, por supuesto, excluidas por los historiadores. No fue sino hasta la época de paz que siguió a las guerras de independencia que nuevos aires impulsaron la música colombiana y la participación de las mujeres en este campo cultural.

Al final de la colonización, la élite emergente con poder político también empezó a tener sus propias reuniones o tertulias en las que la música cumplió un rol central. José María Vergara se refiere en su relato "Las tres tazas" (1863) a la invitación a 'tomar un refresco' que hiciera doña Tadeo Lozano, Marquesa de San Jorge, la noche del 13 de mayo de 1813 a un grupo de "Treinta caballeros y veinticinco señoras y señoritas", en despedida de Antonio Nariño: "Asistieron cincuenta personas de lo más escogido que había en la ciudad: Nariño, Baraya, Torres, Madrid y otros personajes por el estilo. Nariño estaba en vísperas de marchar al Sur con su valiente ejército; y la marquesa de San Jorge quería darle por despedida, lo que se llamaba entonces un refresco, es decir, una taza de chocolate" (1863, web). Una ocasión propicia para hacer gala de ademanes nobiliarios de una élite en ascenso: "Era el traje de los caballeros, zapato de hebilla, media de seda, pantalón rodillero con hebilla de oro, chaleco blanco y casaca sin solapas, según la última moda, y que era llamada Bonapartina. El traje de las señoritas consistía en camisón de seda de talle muy alto y descotado, mangas corridas, falda estrecha" (1863, web). La destreza en la danza y la sensibilidad por los nuevos ritmos fue evidente: "Apenas llegaron al salón rompió la música de cuerda que estaba prevenida, con una alegre contradanza que hizo saltar de alegría a todos los que la escuchaban. Puso la contradanza el elegante Madrid con la hermosa doña Genoveva Ricaurte. Las figuras fueron paseo, cadena y triunfo, en la primera parte; y en la segunda alas cruzadas, paso de Venus y ruedas combinadas. Tras de la contradanza se bailaron un capitusé, un zorongo, un ondú y dos cañas" (1863, web).16 En estas tertulias, que protagonizaron varias mujeres -como la Marquesa de San Jorge-, se fraguaba, según fue percibido luego por las mismas autoridades del reino, la transición política hacia una nueva república. "Cuatro años después-dice Vergara y Vergara-todos los hombres de aquella tertulia, menos dos, habían sido fusilados: todas las mujeres, menos tres, habían sido desterradas" (1863, web).

La salida de las prácticas musicales femeninas del ámbito familiar, es decir, la profesionalización del canto, tiene origen en el contexto neogranadino en la participación de las mujeres en la actividad teatral (Bermúdez 2000, 85-90). Es en el teatro - es decir, bajo el disfraz de una farsa-, donde las prácticas musicales femeninas seculares alcanzan un espacio público de reconocimiento. En los espacios cerrados, sin embargo, se venía cultivando el gusto musical y las mujeres eran cada vez más protagonistas, como se deja ver con el caso de la Marquesa de San Jorge.17 De acuerdo con las investigaciones de Perdomo (1980, 47-48), doña Rafaela Izasi importó uno de los primeros piano-forte a Santafé. La llegada del piano para la Marquesa de San Jorge fue muy famosa en Santafé y se constituyó en un acontecimiento cultural que puso además de presente la enorme influencia política de las mujeres desde el espacio íntimo. Más adelante, en el cenit del siglo XIX, cuando se iban a plantear la idea de una música nacional, su registro se iba a obliterar y se consideró su pasado casi inexistente. Sin embargo, es claro que las prácticas musicales en las que intervinieron mujeres no solo fertilizaron la cultura musical de la época, sino que también consiguieron reafirmarse con nombre propio durante el periodo colonial.

\section{Algunas conclusiones}

Aun considerando los importantes cambios que se produjeron en España con las reformas borbónicas y con el influjo 
de países Ilustrados como Francia e Italia, la colonia neogranadina hubo de esperar un siglo para escapar de las normas conservadoras de la cultura imperial. ${ }^{18}$ En la mayoría de los estudios sobre la vida cotidiana de la mujer por esas calendas, su participación en la vida musical aún es desconocida, cuando no silenciada. Sabemos, por el circuito cultural colonial en el que está incluido el contexto neogranadino, que las mujeres fueron relevantes en el desarrollo de un cultura musical en la Colonia. Aunque se requieren más estudios sobre este asunto, escudriñando en diferentes fuentes hemos logrado exponer aspectos interesantes de la presencia de las mujeres en la historia de la música en el Nuevo Reino de Granada. Existen indicios fuertes para demostrar que la relación de las mujeres con la música en la Colonia, en especial de las que habitaban los centros urbanos, fue diversa y en muchos sentidos frecuente. Ya sea en el convento, en los espacios íntimos y públicos, o en reuniones sociales promovidas por una élite cada vez más interesada en promover mecanismos de distinción social, la música acompañó numerosas actividades en las que las mujeres participaron y fueron protagonistas como productoras, consumidoras o agentes pasivas. Podría decirse incluso que la música fue definitiva en la construcción de algunas subjetividades femeninas. Faltan muchas más investigaciones acerca de la presencia de la música en comunidades rurales, y entre indígenas y negritudes, en las que la documentación es aún más escasa. Lo cierto es que la cultura musical neogranadina no solo fue producto de la hibridación de las herencias indígenas, negras e hispánicas, sino igualmente un espacio de reconfiguración de las identidades sociales, en el que las mujeres también subvirtieron su papel, a pesar de la discriminación y la subvaloración de su quehacer, a las que de manera particular eran sometidas entonces.

\section{Obras citadas}

Acosta P., Carmen Elisa. 1997. "Crimen colonial: un Oidor literario en el siglo XIX”. Literatura: teoría, historia, crítica 1: 182209. https://revistas.unal.edu.co/index.php/lthc/article/view/46316.

Baranda Leturio, Nieves. 2013. "Producción y consumo poéticos en los conventos femeninos". Bulletin hispanique 115: 165183. https://journals.openedition.org/bulletinhispanique/2421

Barrado Barquilla, José. 1995. Los Dominicos y el Nuevo Mundo, siglos XVIII-XIX: actas del IVo Congreso Internacional, Santafé de Bogotá, 6-10 septiembre 1993. Salamanca: Editorial San Esteban.

Bénassy-Berling, Marie-Cécile. 1996. "Sor Juana Inés de la Cruz, une expression des élites culturelles mexicaines du XVIIe siècle”. Caravelle - Les élites latino-américaines 67: 23-36. https://doi.org/10.3406/carav.1996.2706

Bermúdez, Egberto. 1995. Historia de la música en Colombia: música indígena, tradicional y cultura musical durante el periodo colonial siglos XVII y XVIII [Informe de investigación]. Bogotá: Instituto Colombiano de Cultura.

---. 1997. "El archivo de la catedral de Bogotá: historia y repertorio". Revista Musical de Venezuela 16 (34): 53 - 64.

--- 2000. Historia de la música en Santafé y Bogotá 1538-1938. Bogotá: Fundación de Música.

Cadenas, Viana. 2005. "La música en la micro-sociedad 'espiritual' de mujeres mantuanas: Convento de la Inmaculada Concepción de Caracas (Siglos XVII- XIX)”. Revista de la sociedad venezolana de musicología, núm. 9 (julio-diciembre): 3-33.

Castillo, V. M. Francisca Josefa de. 1968. Obras completas de la Madre Francisca Josefa de la Concepción de Castillo. Editadas por Darío Achury Valenzuela. 2 vols. Bogotá: Banco de la República.

Cordovez Moure, José María. 1899. Reminiscencias de Santafé y Bogotá. Bogotá: Librería Americana.

García Sánchez, Bárbara. 2007. De la educación doméstica a la educación pública. Transiciones de la Colonia a la República. Bogotá: Universidad Distrital Francisco José de Caldas.

Grebe, María Ester. 1969. “Introducción al estudio del villancico en Latinoamérica”. Revista musical chilena 107: 7-31. https:// revistamusicalchilena.uchile.cl/index.php/RMCH/article/view/10807 
Haefer, Richard J. 2018. "Iniciación a la música del Nuevo reino de Granada". Revista Memoria 19 (Archivo General de la Nación): 42-61. https://www.archivogeneral.gov.co/sites/default/files/Estructura_Web/5_Consulte/Recursos/Revista_ memoria/Memoria_19.pdf

Hernández-Torres, Ivette. 2003. "Escritura y misticismo en los Afectos espirituales de la madre Castillo". Revista Iberoamericana LXIX, núm. 204 (julio-septiembre-): 653-665. https://revistaiberoamericana.pitt.edu/ojs/index.php/ Iberoamericana/article/view/5644

Herrera, Clara E. 2013. Las místicas de la Nueva Granada: Tres casos de búsqueda de la perfección y construcción de la santidad. Barcelona: Cecal/Paso de Barca.

Isaza, Alejandra. 2010. Suite para los sonidos: música en Medellín, siglos XVII y XVIII. Medellín: Editorial Eafit.

Lamus Obregón, Marina, ed. 2012. En busca del Coliseo Ramírez: Primer teatro bogotano. Bogotá: Taller de Edición Rocca.

"Las Clarisas en Bogotá". 1929. Miscelánea de historia compilada por misioneros Hijos del Inmaculado Corazón de María. Bogotá: Escuela Tipográfica Salesiana.

Marín-López, Javier. 2017. "Música, nobleza y vida cotidiana en la Hispanoamerica del siglo XVIII: hacia un replanteamiento". Acta Musicológica 89 (2): 123-144. https://dialnet.unirioja.es/servlet/articulo?codigo=6318962

Martínez Carreño, Aida. 2003. "Un baile de máscaras en el coliseo de Santafé, 1803”. Revista Credencial Historia 168: 2-3. https:/www.banrepcultural.org/biblioteca-virtual/credencial-historia/numero-168/un-baile-de-mascaras-en-el-coliseo-desantafe-1803

Miranda, Ricardo. 1996. “Aves, ecos, alientos y sonidos: Juana Inés de la Cruz y la música”. Revista de Musicología 19, núm. 1/2 (Enero-Diciembre): 85-104. DOI: 10.2307/20797092

Muriel, Josefina. 2000. Cultura femenina novohispana. México: Universidad Nacional Autónoma de México, Instituto de Investigaciones Históricas (Serie Historia Novohispana, 30). http://www.historicas.unam.mx/publicaciones/publicadigital/ libro/cultura/femenina.html

Muriel, Josefina y Luis Lledías. 2009. La música en las instituciones femeninas novohispanas. México: Universidad Nacional Autónoma de México.

Ortiz, Juan Francisco. 1845. "El Oidor Cortés de Mesa". En Museo de cuadros de costumbres vol. III, Biblioteca Virtual Banco de la República. http://babel.banrepcultural.org/cdm/ref/collection/p17054coll10/id/2512

Ortiz, Mario A. 2007. "La musa y el melopeo: los diálogos trasatlánticos entre Sor Juana Inés de la Cruz y Pietro Cerone". Hispanic Review 75 (3): 243-264.

Ossola, Carlo. 2013. "Cap 1. Caminos de la mística: siglo XVII-XX”. En Victoria Cirlot Valenzuela y Vega, Amador. Mística y creación en el s. XX. Barcelona: Editorial Herder.

Perdomo Escobar, José Ignacio. 1980. Historia de la música en Colombia. Bogotá: Plaza y Janes Editores Colombia.

Puerta Zuluaga, David. 1988. Los caminos del tiple. Bogotá: Ediciones AMP.

Ramos López, Pilar. 2003. Feminismo y música: Introducción crítica. Madrid: Narcea, S. A. de Ediciones.

Restiffo, Marisa. 2018. "De la música al poder: los oficios musicales como estrategia de ascenso político en el monasterio de Santa Catalina de Sena (Córdoba, siglo XVIII)”. Revista Argentina de Musicología 19: 143-173. https://core.ac.uk/ download/pdf/11860587.pdf

Rodríguez Freyle, Juan. [1856] 1980. El Carnero. Bogotá: Editorial Bedout, S. A. 
Sans, Juan Francisco. 2012. "Baile y poder en la Colombia de Bolívar". Ensayos: Historia y Teoría del Arte 22: 136-168. https://revistas.unal.edu.co/index.php/ensayo/article/view/46167

Silva, Renán. 2001. "El sermón como forma de comunicación y como estrategia de movilización. Nuevo Reino de Granada a principios del siglo XVII". Revista Sociedad y Economía 1 (septiembre): 103-130. https://core.ac.uk/download/ pdf/11860587.pdf

Simón, Pedro Fray. 1891. Noticias Historiales de las conquistas de tierra firme en las Indias. Bogotá: Casa Editorial de Medardo Rivas.

Sopeña, Federico. 1970. Historia de la música. Madrid: E.P.E.S.A.

Stevenson, Robert. 1962. "La música colonial en Colombia". Revista Musical Chilena 16: 153-171. http://www.laguitarra-blog. com/wp-content/uploads/2012/06/musica-colonial-colombia.pdf

Toquica, Constanza y Restrepo, Luis Fernando. 2001. "Las canciones del coro alto de la iglesia del Convento de Santa Clara". Cuadernos de Literatura 6 (12): 90-117. https://revistas.javeriana.edu.co/index.php/cualit/article/view/8031/0

Vera A., Alejandro. 2004. "La música en el convento de La Merced de Santiago de Chile en la época colonial (siglos XVIIXVIII)”. Revista Musical Chilena 58, núm. 201: 34-52.

Vergara y Vergara, José María. 1863. “Las tres tazas”. https://www.biblioteca.org.ar/libros/1291.pdf

Yardley, Anne Bagnall. 1986. “Full weel she soong the service dyvyne': The Cloistered Musician in the Middle Ages.” Women Making Music: The Western Art Tradition, 1150-1950. Editado por Bowers, Jane, y Judith Tick. Urbana: University of Illinois Press, 15-38.

\section{Notas}

1. La primera comunidad femenina en Nueva Granada, el Convento de Santa Clara en la ciudad de Tunja, fue fundada en 1573 (Herrera 2013, 29).

2. Existen pruebas de que a las monjas del Monasterio de las Huelgas (Burgos) — de gran importancia durante la Edad Media— se les instruía en cantos polifónicos (Yardley 1986, 25). Hildegard of Bingen (1098-1179), reconocida mística y autora del siglo XII, aparte de producir varias obras teológicas y tratados médicos y científicos, compuso el texto y la música de obras sagradas y dramáticas. La santa dejó un cuerpo sustancial de canto llano, que ha sido de interés para varios investigadores (Yardley 1986, 27-28).

3. Un análisis general de los poemas de sor Juana Inés de la Cruz, donde la música juega un papel importante, se encuentra en "Aves, ecos, alientos y sonidos: Juana Inés de la Cruz y la música" de Ricardo Miranda (1996). Por su parte, Mario A. Ortiz en "La musa y el melopeo: los diálogos trasatlánticos entre Sor Juana Inés de la Cruz y Pietro Cerone" (2007), estudia el elemento musical en la poesía de la "Décima Musa," con base en sus diálogos con el teórico musical italiano.

4. De acuerdo con Federico Sopeña (1970), Carlos V muestra desde los últimos años de su reinado un aprecio singular por la música sacra. Para Felipe II, el gusto de la música religiosa concuerda con el retrato que poseemos de su personalidad, "adquiere caracteres más precisos de postura espiritual". Felipe II "prohíbe los villancicos en las iglesias y urge a los sínodos que se convocan para el cumplimiento de las composiciones de Trento la purificación de la música religiosa." Bajo Felipe III continúa la protección a la música religiosa $(1970,16-17)$. Si bien los monarcas españoles específicamente promovían el crecimiento de la música sacra, no se puede ignorar que los desarrollos musicales se adaptaban a las particulares condiciones donde se interpretaba la música, y es factible la creencia de que tal digresión se extendió a la música secular. En el Siglo XVI español, la música alcanza su máximo esplendor con la polifonía religiosa, pero en los romances y villancicos ya se percibe un sello popular "constante" (Sopeña 1970, 21).

5. El estudio de los vínculos entre las fuentes musicales conservadas en Lima y Santiago ha permitido señalar con precisión 
algunas piezas que sin duda fueron enviadas a Chile desde Lima, la capital del virreinato (Vera 2004, 17). Curiosamente, en algunos conventos hispanoamericanos, como es el caso del Convento de la Inmaculada Concepción de Caracas, paralelamente a la vida del espacio sagrado, se llevaba a cabo una vida de fiestas y diversiones con participación musical, que eran continuamente censuradas. A pesar de esto, las ceremonias festivas y diversiones del convento, no dejaban de llevarse a cabo, de ahí sus constantes prohibiciones, en particular, el canto de villancicos (Cadenas 2005, 10).

6. Es interesante anotar en este punto que mientras "Herrera se dedicaba a los géneros latinos más serios, uno de sus subordinados, Juan Ximenes, creaba la compensación convirtiendo al villancico vernáculo en su dominio". Existen hoy en día villancicos compuestos por Ximenes que datan de 1709 a 1724, alguno de ellos amalgama de "un texto picaresco y una música extraordinariamente garbosa" (Stevenson 1962, 161). Más información sobre Juan de Herrera se encuentra en la Historia de la música en Colombia (Bermúdez 1990, 137-140).

7. Esto se hacía de acuerdo con los patrones culturales y éticos de las élites europeas. Las damas de la aristocracia española, durante los siglos XVII y XVIII se dedicaban a recitar versos y a tocar instrumentos musicales (Fraile 2004, 87).

8. A partir de San Juan de la Cruz la música va a ser el signo de la experiencia mística y la manera como se manifiesta con el contacto con la divinidad (Ossola 2013). En el caso de la monja Castillo, el espíritu religioso era concebido más que discurso como una forma de 'música' que alteraba su comprensión, atravesaba su corporalidad y la convertía a ella misma en instrumento de la pasión religiosa. Su escritura era manifestación de esa "música" íntima que debía leerse también en clave sensible: "Entendí que el comparar el alma a un instrumento de flautas muy delgadas, se entendía por todo lo que llevo escrito; porque como el aire o aliento del que toca, es el que oye en aquel instrumento, así lo que aquí hubiere de Dios, solo es lo que su majestad envía de su espíritu, por un instrumento de caña, sin virtud para nada, etc. (cit. en Hernández-Torres 2003, 658).

9. El capítulo décimo de El Cortesano de Castiglione se titula así: "Como al perfecto cortesano le pertenece ser músico, así en saber cantar y entender el arte, como en tañer diversos instrumentos" (Sopeña 1970, 19).

10. Solo hasta 1823 existe registro de una escuela dirigida a mujeres en la ciudad de Cartagena que incluye la formación musical en su currículo. "Cavalier tiene el honor de prevenir al respetable público de Cartagena, ha destinado con permiso del gobierno la casa que hace esquina frente la de Santo Domingo y la calle de la factoría para establecer una escuela de niñas de la edad de cinco años para arriba, en que se promete enseñarles a hablar y escribir con principio los idiomas francés y castellano, coser, marcar, bordar, y tocar el piano, y la música vocal. Aviso al público" (cit. en García 2007, 253).

11. Este caso es narrado por primera vez por Rodríguez Freyle en el capítulo XII de El Carnero (1636-1638). Luego se encuentran dos referencias "oficiales" a la historia del crimen cometido por el Oidor Cortés de Mesa en los siglos XVII y XVIII: la de Juan Flórez de Ocariz en Las genealogías del Nuevo Reino de Granada (1671); y la de Fray Antonio de Zamora en su Historia de San Antonio del Nuevo Reino de Granada (1701)" (Acosta 1997, 186). En el siglo XIX, el caso fue narrado por los historiadores como José Antonio de Plaza, José Manuel Groot y Pedro María Ibáñez y, paralelamente, se elaboran obras literarias sobre el tema tales como El Oidor de Santafé de Juan Francisco Ortiz (1854), El Oidor. Romance del siglo XVI de José Antonio de Plaza (1850), y El Oidor. Drama histórico de Jermán Gutiérrez de Piñeres (1865) (Acosta 1997, 188-189). Entre estas obras, hemos escogido la de Juan Francisco Ortiz, pues provee una imagen "musical," que aunque ficcional, presenta un cuadro verosímil sobre los encuentros sociales en el mundo colonial, si tenemos en cuenta, por ejemplo, que Rodríguez Freyle nos deja saber que en las casas de los individuos socialmente reconocidos había espacios dispuestos para el baile y la cena, especialmente en la sala $(1980,65)$. Para un completo análisis de los diferentes escritos sobre este caso ver el artículo "El crimen de Cortés de Mesa en nuestra literatura" (1997) de Carmen Elisa Acosta.

12. Los bailes de máscaras, fiestas populares a las cuales se accedía comprando una boleta, habían sido introducidas en Madrid por el conde de Aranda alrededor de 1775. En estos bailes la nobleza se confundía durante unas horas con el público de la fiesta (Martínez 2003, 1).

13. Una relación de todas las Prevenciones que se deben observar en los dos bayles de máscaras que el comercio de esta capital ofrece al feliz arribo del Excmo. Señor Virrey Antonio Amar y Borbón se encuentran en el artículo "Un baile de máscaras en el coliseo de Santafé" por Aida Martínez Carreño (2003). Vale la pena anotar que entre otras prevenciones están la de prohibir que los hombres se vistan de mujeres, y de que tanto hombres como mujeres fueran sin máscara, es decir como tapados o tapadas. Ver también “En busca del Coliseo Ramírez” por Marina Lamus Obregón (2012).

14. En ese momento la comunidad de capuchinos tenía mucha influencia en la sociedad santafereña. Secundando las ideas del 
Arzobispo, le hacía cruda guerra a la obra del teatro; se dice que, entre los padres, hubo uno, fray Matías Callosa, escandalizado por las tonadillas interpretadas por Nicolasa Villar, quien hizo época en sus bailes, tonadas y copla, se fue en contra de ella desde el púlpito (Perdomo 1980, 49).

15. Leemos en Feminismo y música que "El caso más conocido es el de las cultísimas cortesanas venecianas, pero también en Gran Bretaña y en España encontramos estrictos códigos morales vinculando actividad musical y comercio sexual. Sin embargo, ni en la Gran Bretaña ni en España las mujeres se limitaron a seguir los consejos de los moralistas e hicieron música fuera de casa..." (Ramos 2003, 72).

16. Vergara y Vergara registra un momento de ruptura con la música y la danza del periodo colonial. Si bien la contradanza y los demás ritmos aludidos en el relato son de la tradición española y eran conocidas desde el siglo XVII, empezaron a popularizarse en buena medida gracias a los 'aires franceses' con los que fueron adoptados estos círculos en los emergentes círculos nobiliarios lo que significó, entre otros rasgos, la paulatina transición a los bailes en pareja, que representa un cambio importante en el manejo del cuerpo y en la visión de la danza. El epítome en el siglo XVIII de los bailes en pareja será, desde luego, el vals, la versión más decantada de la sensibilidad burguesa (Sans 2012, 138). Como advierte el musicólogo Juan Sans, llama la atención que en el baile relatado por Vergara y Vergara se excluya de los bailes de la corte al minueto "resabio de la aristocracia más rancia” (138). Ver "Baile y poder en la Colombia de Bolívar" (2012).

17. Javier Marín-López (2017), en su artículo "Música, nobleza y vida cotidiana en la Hispanoamérica del siglo XVIII: hacia un replanteamiento," aporta evidencias que sugieren que después de la mitad del siglo XVIII hubo una importante actividad de música de cámara en el ámbito doméstico, en una élite social urbana ligada a estrategias de distinción simbólica propias del ideario iluminista (125). Aunque el eje de la investigación es Nueva España, menciona algunos casos en otros lugares de Hispanoamérica que confirmarían su hipótesis, entre ellos el caso de la Marquesa de San Jorge, como gestora de una actividad musical en la Nueva Granada (136).

18. Coincidimos con Bermúdez en esta apreciación. El autor además enseña un ejemplo importante de dicho atraso: "Solo en virtud de esto es posible explicar la presencia de vihuelas en nuestro territorio (en Santafé y Tocaima) en 1757, 1760 y 1761 cuando hacía más de un siglo y medio que habían dejado de usarse en la metrópoli” (181). Desde principios del renacimiento, los vihuelistas españoles dan un paso decisivo como protagonistas de la música "moderna" europea (Sopeña 1970, 19). El siglo XVII vive todavía el auge de la vihuela y el laúd, y solo hasta fines de este siglo se plantea la existencia de una música instrumental pura (Sopeña 1970, 30). 